\title{
As Conversas de JANE
}

JoÃo PaUlo André*

\begin{abstract}
Conver na, então a dar os primeiros passos. A sua autora foi Jane Haldimand Marcet (1769-1858), senhora de uma personalidade comunicativa e de um espírito averiguador e objetivo. As palestras a que assistia na Royal Institution, proferidas pelo famoso Humphry Davy, e que depois Ihe eram explicadas pelo marido - o médico e químico Alexander Marcet - estiveram na génese de Conversations on Chemistry, escrito na forma de diálogos ficcionais entre uma professora e duas alunas, destinado acima de tudo a levar os conhecimentos da Química a outras mulheres. Durante várias gerações o livro foi um best seller, tanto na Europa como nos Estados da América. Ainda hoje se publica.
\end{abstract}

\section{Jane Haldimand Marcet}

Jane Haldimand nasceu em Londres em 1769 (Figura 1), filha de mãe inglesa e pai suíço, um banqueiro e homem de negócios de sucesso. Jane e os seus onze irmãos cresceram num ambiente cultural e intelectualmente estimulante; a educação escolar foi-lhes dada em casa pelos melhores precetores da época. De acordo com a convicção do pai, algo liberal, rapazes e raparigas deviam receber a mesma instrução; assim, Jane e os irmãos aprenderam Filosofia Natural, História e Línguas, a par da Música, Arte e Dança [1].

Jane, que desde cedo revelou uma grande avidez para o conhecimento, era possuidora de um espírito sagaz e pragmático que não se coadunava com matizes discursivos de natureza subjetiva, donde lhe vinha uma certa propensão para um entendimento quase literal das palavras. É frequentemente narrado um episódio, algo caricato, bem ilustrativo da sua forma de pensar: em criança terá um dia ouvido a avó queixar-se de um relógio que não funcionava bem, pelo que de bom grado o trocaria por um guinéu. Jane, sem meias medidas, no dia seguinte apresentou-se à avó com um orgulhoso guinéu e meio - tanto quanto Ihe tinha rendido o velho relógio num relojeiro - mas, para sua grande admiração, em vez do elogio que

\footnotetext{
* Departamento/Centro de Química, Universidade do Minho, Campus de Gualtar

4710-057 Braga

E-mail: jandre@quimica.uminho.pt
}

achava merecer por um negócio tão rentável, ouviu uma forte reprimenda da velha senhora que, ao mesmo tempo, Ihe ensinava que nem tudo o que se diz deve ser levado à letra. Ao longo da vida Jane manteria esta quase inépcia para conceber que alguém dissesse uma coisa, quando queria dizer outra [2].

Desde muito nova, Jane teve a oportunidade de privar com importantes figuras do mundo da política, das artes, da ciência e da literatura - tais eram os frequentadores dos jantares e serões "lluminados" da casa de seus pais. Quando, aos 15 anos, subitamente perdeu a mãe, que com 39 anos sucumbiu a um complicado parto, ficou assente na família que daí em diante seria ela a responsável pela organização dos serões sociais dos Haldimand. Foi num desses serões que Jane conheceu o suíço Alexander Marcet, com quem casaria em 1799 e de quem teria quatro filhos. Dessa união com Alexander, médico e químico destacado, resultou a abertura da casa dos Haldimand-Marcet a figuras tão notáveis como os químicos Berzelius, Wollanston e Humphry Davy, o botânico Augustin de Candolle, o matemático Horace Benedict de Saussure, o físico Auguste de La Rive e o economista político Thomas Malthus [1]. Jane também manteve o seu próprio salão, destinado a incentivar o estabelecimento de redes de comunicação entre mulheres intelectuais. Correspondeu-se com a matemática e astrónoma irlandesa Mary Somerville (1780-1872), também ela uma des- tacada escritora e divulgadora de ciência [3]. Do seu vasto círculo faziam ainda parte a romancista irlandesa Maria Edgeworth (1768-1849) e Harriet Martineau (1802-1876), que serão referidas adiante. Conta-se que Jane Marcet e Maria Edgeworth ficaram amigas no seguimento de uma carta de gratidão por esta enviada à autora de Conversations, por alegadamente o seu livro ter salvado a vida da irmã, que incidentalmente ingerira um ácido, pois alguém se recordara de nele ter lido que os ácidos podiam ser neutralizados com magnésia [4].

Para além de Conversations on Chemistry - um dos primeiros textos didáticos de ciência moderna - Jane teve uma vasta produção literária de ensino e divulgação do conhecimento que incluiu títulos como Conversations on Polytical Economy (1816), Conversations on Natural Phylosophy (1819),

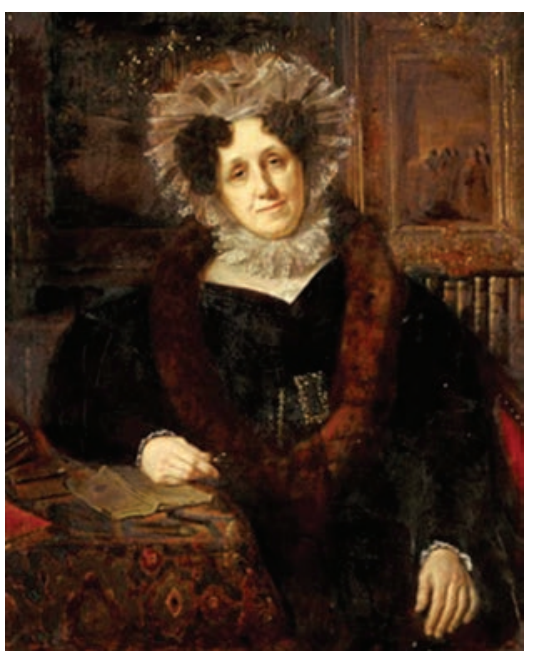

Figura 1 - Jane Haldimand Marcet (1769-1858) 
Conversations on Language (1844) e vários livros para crianças [4].

Jane Marcet morreu em Londres, aos 89 anos.

\section{Alexander Marcet}

Alexander John Gaspard Marcet (1770-1822), Figura 2, natural de Genebra, bem jovem partiu para Inglaterra como exilado político, no decurso das convulsões da Revolução Francesa. Em 1797, obteve o diploma de médico pela Universidade de Edimburgo e dois anos depois desposou Jane Haldimand e licenciou-se em Medicina pelo Colégio Real de Médicos; em 1800 obteve a cidadania inglesa. Em 1805 colaborou na fundação da Sociedade Médico-Cirúrgica de Londres, uma instituição que mantinha estreitos contactos com médicos e químicos de outras nações, de entre os quais o grande químico sueco Jöns Jacob Berzelius (1779-1848). Foi por essa altura que a atenção de Alexander Marcet se focou na análise de águas minerais, o que lhe conferiu a experiência necessária para o trabalho que o tornaria famoso: a análise química de fluidos de origem animal e de cálculos urinários, que publicou sob o título de An Essay on the Chemical History and Medical Treatment of Calculous Disorders (Londres, 1819). A própria técnica utilizada nesse trabalho, a semimicroanálise, constituía uma novidade para a época; Alexander, contudo, nunca deixou de reconhecer o mérito do pioneirismo de William Hyde Wollaston no estudo da composição de cálculos urinários [1, 5].

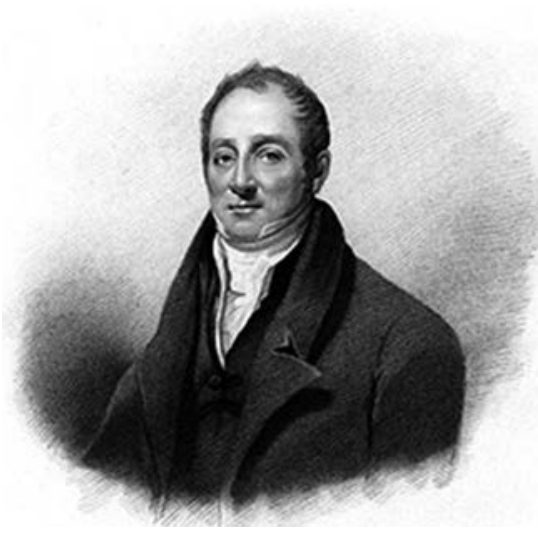

Figura 2 - Alexander Marcet (1770-1822)
De 1804 a 1819, Alexander exerceu a profissão de médico e químico no Hospital de Guy - uma importante escola Iondrina de Medicina - onde, nas aulas de Química que lecionava, introduziu uma componente de identificação e caracterização química de cálculos urinários, a qual complementava com demonstrações experimentais. Alexander Marcet pode justamente ser considerado como um dos grandes impulsionadores desta, então recente, metodologia pedagógica, sobretudo por via indireta. Aquando da visita que fez a Londres, em 1812, Berzelius ficou tão impressionado com as lições de Alexander, que decidiu ele próprio adotar a mesma metodologia pedagógica no Instituto Karolinska, em Estocolmo. Os dois cientistas mantiveram uma correspondência regular e voltaram a encontrar-se mais duas vezes.

Alexander Marcet, que morreu aos 52 anos, é recordado sobretudo como um dos pioneiros da aplicação da Química à Fisiologia e à Medicina, em particular quanto ao uso da análise química para obtenção de diagnósticos clínicos fiáveis $[1,5]$.

\section{De LaVoIsier Às palestras da ROYal INSTITUTION}

As últimas três décadas do séc. XVIII constituíram uma grande revolução na Química: os avanços da Química Pneumática tinham centrado a atenção sobre o oxigénio, permitindo dar a machadada final na convicção de que o ar e a água eram elementos. Em 1789, o Traité Élémentaire de Chimie de Antoine Laurent Lavoisier (1743-1794) veio definitivamente consagrar a Química como uma ciência moderna.

No tempo que mediou entre a publicação do Traité e Conversations on Chemistry, uns escassos dezasseis anos, assistiu-se progressivamente à aceitação das novas teorias e atitudes perante a Química, nomeadamente: a utilização sistemática dos métodos quantitativos, a eliminação absoluta da teoria do flogisto (embora houvesse entretanto o óbice do calórico!), a lei da conservação da massa, a teoria da combustão, a noção de elemento e um novo sistema de nomenclatura.
O período que se seguiu à morte de Lavoisier foi também marcado, não surpreendentemente, por enormes avanços, em particular na análise quantitativa (graças, sobretudo, aos contributos de Martin Heinrich Klaproth (1743-1817), na Alemanha; de Louis Nicolas Vauquelin (1763-1829), em França, e de William Hyde Wollaston (1766-1828), em Inglaterra, responsáveis pela descoberta de vários elementos metálicos).

De França vieram ainda os contributos maiores de Claude Berthollet (1748-1822), através dos estudos que conduziram à enunciação da lei da ação da massa (a qual viria a ser formulada em 1864 pelos noruegueses Cato Maximilian Guldberg e Peter Waage) e de Joseph-Louis Proust (1754-1826), com a lei das proporções definidas. Em Inglaterra, John Dalton (1766-1844), entrando na era moderna da teoria atómica, assumiu que os elementos se combinam entre si por relações simples de massas (1803), mas cometeu o erro de atribuir arbitrariamente valores às proporções de combinação. A lei da combinação dos volumes dos gases, enunciada em 1808 por Louis Joseph Gay-Lussac (1778-1850) - sugerindo que todos os gases deveriam ter o mesmo número de átomos num determinado volume - poderia ter constituído a chave conciliadora entre Dalton e Gay-Lussac, contudo, na época, não houve quem o soubesse fazer. Em Itália, em 1811, Amedeo Avogadro (1776-1856), distinguindo pela primeira vez entre átomo e molécula, oferecia a solução para a resolução do diferendo Dalton/ Gay-Lussac, mas acabaria por ser uma voz isolada e ignorada durante quase cinco décadas (apesar do esforço levado a cabo por André Marie Ampère, em 1814, para a sua aceitação). Entretanto, em Estocolmo, Berzelius fez progressos no isolamento de novos elementos (ao cério, descoberto em 1803, seguir-se-iam o selénio, tório, silício, zircónio e titânio) e na determinação de massas atómicas (a massa do carbono passou para 12, a do nitrogénio para 14 e a do oxigénio para 16). Todavia, neste campo, o seu sucesso foi mais moderado porque, não raramente, deparava-se com grandes problemas de interpretação dos resultados da sua investigação, 
decorrentes de uma teoria atómica, ainda, bastante incipiente (o uso dos equivalentes superava em parte esta limitação). A Berzelius deve-se ainda a moderna notação química ao ter sugerido, em 1811, o uso dos atuais símbolos dos elementos.

Em Bristol, na Instituição Pneumática, entre 1799 e 1802, foram estudados os efeitos de vários gases sobre os seres humanos; dessa investigação sobressaiu o nome de Humphry Davy (1778-1829), verdadeiro herói romântico inglês, que à enorme habilidade para a Química juntava ainda dotes para a poesia. Em plena época da descoberta da eletricidade - Alessandro Volta (1745-1827) tinha apresentado em 1800 a primeira pilha elétrica - Davy viria a evidenciar-se na eletrólise de sais, isolando o potássio e o sódio, em 1807, e o cálcio, estrôncio, bário e magnésio em 1808 [6-8].

Entretanto, em 1801, quando as palestras públicas de Humphry Davy começavam a fazer furor na recentemente criada Royal Institution, aquele que viria a ser o genial Michael Faraday (1791-1867) era ainda uma criança.

As lições públicas de Humphry Davy, que incluiam demonstrações experimentais e às quais se acedia mediante o pagamento de uma entrada, tornaram-se tão famosas que passou a ser chique frequentá-las; a burguesia elegante de Londres e a aristocracia não as perdiam - Jane e Alexander Marcet também não! Para a maioria dos espectadores, em particular as senhoras, estas sessões constituíam uma espécie de entretenimento circense; porém, para Jane, eram muito mais do que um espetáculo: achavaas verdadeiramente fascinantes, pelo conhecimento científico que lhe traziam, e o seu desejo era poder entendê-las integralmente.

Assim, deu início à realização de algumas experiências científicas na sua própria casa (para o que contava com o auxílio e as explicações do marido). Daí até ter sentido que outras pessoas, em particular as mulheres, deviam poder aceder a informação compreensível sobre os factos da Química e das suas descobertas para o bem-estar da sociedade, foi um curto passo.

\section{Jane \& Cia}

A proporção dos impactos que a obra de divulgação científica encetada por Jane Marcet iria atingir ao longo do séc. XIX era totalmente inédita para a época, todavia não era a primeira vez que, de forma direta ou indireta, se verificavam contributos "no feminino" para a propagação do conhecimento científico. Na França do séc. XVIII, das mais diversas formas, contribuíram para a divulgação da ciência figuras tão relevantes como Émilie du Châtelet, Claudine Picardet e Marie-Anne Pierrette Paulze Lavoisier.

Émilie du Châtelet (1706-1749) foi uma matemática, física e escritora do lluminismo, que se destacou sobretudo pela tradução para francês da genial obra de Isaac Newton Principia Mathematica, onde incluiu anotações e comentários da sua própria autoria. Esta tradução, que só foi publicada dez anos após a sua morte, ainda hoje é considerada a versão francesa de referência. Ao longo da sua atividade literária e de tradução, a Marquesa de Châtelet advogou o direito das mulheres à educação, por entender que, só assim, estas poderiam, à semelhança dos homens, destacar-se nas artes e nas ciências [8, 9].

Claudine Picardet (1735-1820) foi também uma personalidade de vulto nos meandros da divulgação científica dos finais do séc. XVIII. Enquanto esposa do General Picardet, manteve um salão famoso, procurado por académicos e intelectuais, onde não se coibia de expor as suas opiniões. Madame Picardet, que trabalhou como assistente de Bernard Guyton de Morveau - amigo e colaborador científico de Lavoisier - com quem viria a casar em segundas núpcias, teve uma atividade intensa como tradutora: três livros e várias dezenas de artigos científicos. O seu trabalho de tradutora não só concorreu para a disseminação da Química (em particular a Química dos sais e dos minerais), como também teve impacto no mundo editorial, tanto no que respeita ao aparecimento de revistas científicas especializadas, como na própria definição de alguns aspetos editoriais inéditos (por exemplo a inclusão da data da primeira publicação dos artigos) [10].
Outra figura que, no presente contexto, não pode ser omitida é Marie-Anne Pierrette Paulze Lavoisier (17581836). Muitos investigadores consideram que Claudine Picardet terá sido o modelo de Madame Lavoisier como mulher participante nas atividades do mundo da ciência. Consciente do seu estatuto de esposa do maior químico mundial do tempo, decidiu aprender Química e aperfeiçoar o domínio do Inglês e do Latim. O seu conhecimento das línguas revelou-se valioso para a tradução de vários artigos e livros, dos quais se destacam Essay on Phlogiston (1787) e Strength of Acids and the Proportions of Ingredients in $\mathrm{Neu}$ tral Salts (1790), do químico britânico Richard Kirwan. Na tradução que fez desta última obra incluiu anotações e comentários da sua lavra. Madame Lavoisier foi ainda a responsável pela correspondência científica do marido (as línguas estrangeiras não eram o seu forte!) com figuras como Pristley e Cavendish. Os seus dotes para as belas artes valeram-Ihe ter sido a autora das gravuras que ilustram o Traité Élémentaire de Chimie. Outro contributo, normalmente menos referido, mas não menos importante, foi o ter sido uma divulgadora ativa das ideias da nova Química através da correspondência que manteve com múltiplas personalidades; empenhou-se em particular no derrube da teoria do flogisto - muito arreigada na sociedade científica da época. Depois da morte de Lavoisier, guilhotinado em 1794, Marie-Anne organizou, em 1805, a publicação de Mémoires de Chimie, uma compilação de escritos do marido e dos seus colaboradores, onde se expunham os princípios da nova Química; a esta adicionou uma introdução do seu próprio punho $[11,12]$.

No contexto da divulgação e popularização da ciência no séc. XIX, a escocesa Mary Sommerville (1780-1872), matemática e astrónoma autodidata, merece um destaque especial, provavelmente de forma só comparável a Jane Marcet - a despeito de terem tido intervenções em planos diferentes, atendendo a que Jane não foi uma cientista. A reputação de Mary começou com a sua tradução de Mécanique Céleste, de Laplace, que desde o primeiro instante, em 1831, se revelou um sucesso de vendas. 
A propósito da popularidade da sua versão, a própria chegou a dizer que tinha traduzido Laplace "da álgebra para a linguagem comum". Mary Sommerville foi também autora de várias obras científicas - tão procuradas por cientistas como por estudantes - das quais, por entrarem no domínio das ciências físicas e químicas, se destacam The Connexion of the Physical Sciences (1834) - que na sua terceira edição refere o trabalho de Michael Faraday, com quem se correspondeu entre 1833 e 1834 - e Molecular and Microscopic Science (1869). Os seus livros tiveram uma influência determinante sobre figuras como James Clerk Maxwell e o seu trabalho foi merecidamente reconhecido na época; Mary Sommerville foi alvo de numerosas honras e louvores, tendo sido eleita membro de várias sociedades científicas, incluindo a Royal Society $[13,14]$.

Outra figura de relevo na divulgação científica no séc. XIX, foi Harriet Martineau (1802-1876), de resto frequentadora do círculo social e intelectual de Jane Marcet. Através da sua atividade de jornalista, escritora e socióloga de orientação feminista - hoje considerada como uma das fundadoras da sociologia - Martineau teve um papel importante na difusão dos novos conhecimentos da economia política da primeira metade do séc. XIX (uma das muitas áreas em que Jane Marcet também interveio). Neste campo, Harriet Martineau destacou-se através de uma série de vinte e cinco novelas publicadas sob o título genérico de Illustrations of Political Economy (1832-1834) [15]. Igualmente se notabilizou pelas suas traduções da obra filosófica de Auguste Comte e por ter sido, desde o primeiro momento da publicação de The Origin of Species (1859), uma apoiante da teoria da evolução de Charles Darwin.

\section{Emily, Caroline e a Sra. B.}

Conversations on Chemistry, a obra que Jane Marcet publicou em dezembro de 1805, sob pseudónimo (embora revelasse que era uma mulher), tinha como principal objetivo divulgar a Química, ensinando-a. O desígnio pedagógico e divulgador da obra é apresentado pela autora no prefácio (foi consultada a quinta edição inglesa - Figura 3) [16]:

"Ao aventurar-se a oferecer ao público, mais particularmente ao feminino, uma Introdução à Química, a autora - uma mulher - entende que deverá dar uma explicação pela iniciativa, tanto mais que o seu conhecimento do assunto é recente, não podendo reclamar para si o título de química."

Conversations, que nas primeiras edições apareceu em dois volumes - o primeiro abordando o que autora designa por "corpos simples", e o segundo os "corpos compostos" - está escrito na forma de diálogos informais entre uma professora, a Sra. B., e as suas duas alunas: a reservada Emily, de treze anos, e a sua irmã de dez, a espontânea Caroline.

Centremo-nos no diálogo seguinte, bem revelador da forma e do espírito da obra (página 2 de [16]):

Caroline: Sra. B., para dizer a verdade não estou muito inclinada a conceber a Química de forma muito favorável, nem sequer acho que me possa entreter muito com ela. Prefiro as ciências que abordam a natureza em grande escala às que se confinam à minúcia dos seus detalhes. Porventura poderão os últimos estudos sobre as propriedades gerais da matéria, ou sobre a revolução dos corpos celestes, ser comparados à combinação de meros compostos? Admito contudo que, na Química, possam existir experiências divertidas e que até nem desgostaria de testar algumas delas, por exemplo a destilação da lavanda ou da água de rosas.

Sra. B.: Minha querida Caroline, prefiro pensar que essa tua antipatia pela Química se deve à ideia bastante limitada que tens dela. Restringes o laboratório de Química ao mero espaço de trabalho do farmacêutico e do perfumista, quando na verdade ele se presta a muitas outras funções úteis. Além do mais, minha querida, de modo algum a Química se confina só ao trabalho das profissões: a natureza também tem o seu próprio laboratório, o Universo, onde os processos químicos ocorrem incessantemente. Estás surpreendida, Caroline! Contudo, asseguro-te que os fenómenos mais maravilhosos e interessantes da natureza são quase todos eles produzidos por forças químicas.
[...] Por conseguinte, decerto compreenderás que [...] uma mulher pode adquirir um conhecimento científico que a levará a interessar-se pelos fenómenos correntes da vida, contribuindo ainda para alargar o seu horizonte de ideias e tornar a contemplação da natureza uma encantadora fonte de instrução.

Ao longo de Conversations, a autora vai dando a conhecer, explicando, os principais conceitos da Química e os seus grandes avanços: as descobertas de Galvani, Volta, Franklin, Rumford, Priestley, Oersted, Berzelius, Berthollet, Cavendish, Lavoisier, Davy, ...

Nos dias atuais, para além do valor histórico intrínseco da obra, Conversations on Chemistry tem ainda algo a dizer-nos: não, obviamente, no que toca à Química propriamente dita (o calor é explicado em termos de "calórico"; as transformações físicas e químicas são discutidas, respetivamente, em termos de "atração de coesão" e de "atração de composição"; o "calórico", a luz e a eletricidade são listados como corpos simples; etc.) mas, antes, pelo seu valor didático. Para este, contribuem de forma exemplar a clareza e a simplicidade do texto. Com efeito, Conversations ainda hoje se publica (Figura 4).

Nas últimas décadas têm sido reconhecidas as vantagens das metodologias de ensino-aprendizagem baseadas na convicção de que a aprendizagem se processa por ciclos, ao longo

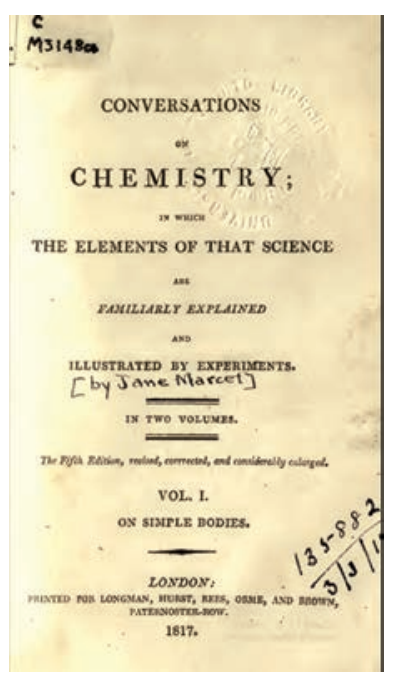

Figura 3 - Frontispício da quinta edição inglesa de Conversations on Chemistry (1817) 
dos quais o estudante tem de ser conduzido pelo professor - desde o nível cognitivo onde se encontra até às novas situações - de forma a poder atingir um novo patamar de conhecimento e de compreensão, idealmente de um nível superior de abstração. As demonstrações e as experiências laboratoriais, bem como o recurso a analogias e a exemplos concretos do quotidiano e da indústria, contribuem para a efetivação destes ciclos de aprendizagem [17]. Em pleno início do séc. XIX, sem dispor das modernas teorias pedagógicas, Jane Marcet, através da Sra. B., conseguiu que fossem alcançados muitos dos resultados que atualmente são esperados dos professores e escritores/ divulgadores de ciência [18]. Se, por um lado, se pode dizer que a autora se destacou no pioneirismo do recurso às demonstrações experimentais [13], por outro, se analisarmos os diálogos - que têm sempre uma extensão adequada ao desenvolvimento do tópico em causa - verifica-se que, por hábito, a Sra. B. introduz os tópicos recorrendo a exemplos conhecidos e a analogias, de seguida apresenta novos conceitos e, finalmente, ajuda as alunas a estabelecer comparações e a tirar conclusões [18]; os diálogos costumam terminar com uma recomendação para que seja revisto um dado assunto, antes de se passar ao seguinte.

No diálogo que se segue, em que a autora recorre ao pão como analogia, é abordado pela primeira vez o con-

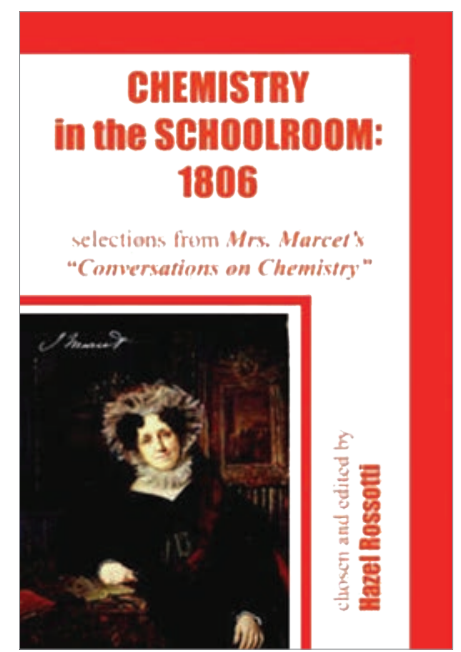

Figura 4 - Capa de uma edição recente de uma seleção de diálogos de Conversations on Chemistry ceito de substância elementar (páginas 7 a 10 de [16]):

Sra. B.: [...] tens de ter em conta que os vários corpos da natureza são compostos por certos princípios elementares, os quais não são em grande número.

Caroline: Sim, eu sei que todos os corpos são compostos por fogo, ar, terra e água: aprendi isso há muito tempo!

Sra. B.: Tens no entanto de fazer um esforço para esquecer isso! Já te falei da grande mudança que ocorreu na Química desde que esta se tornou uma ciência regular ... Um corpo elementar é o que não pode ser decomposto, isto é, separado noutras substâncias. O fogo, o ar, a terra e a água são todos eles suscetíveis de decomposição.

Emily: Pensava que decompor um corpo era dividi-lo nas suas partes mais minúsculas. Assim, não entendo como é que uma substância elementar não pode ser decomposta tal como as outras.

Sra. B.: Não entendeste bem a ideia de decomposição; é muito diferente da simples divisão, que unicamente reduz um corpo às suas partes. A decomposição separa-o nos vários ingredientes ou materiais de que é composto. Consideremos um pão: se separássemos os vários ingredientes de que é feito - a farinha, o fermento, o sal e a água o resultado seria muito diferente do de cortar o pão em pedaços ou de o esmigalhar.

Emily: Compreendo agora muito bem ...

Caroline: Mas a farinha, a água e os outros materiais do pão, de acordo com a definição, não são substâncias elementares?

Sra. B.: Não minha querida. Eu referi o pão, para ilustrar a ideia, mais por ser uma comparação familiar do que propriamente um exemplo.

As substâncias elementares de que um corpo é composto são as chamadas partes constituintes do corpo. Se o decompusermos, iremos, por conseguinte, separar as suas partes constituintes. Se, pelo contrário, dividirmos um corpo cortando-o em pedaços, ou mesmo se o triturarmos ou martelarmos até ficar reduzido ao mais fino pó, cada uma dessas pequenas partículas será ainda uma porção [...] do corpo; estas designam-se por partes integrantes. Consegues ver a diferença?
Emily: Sim, perfeitamente: decompomos um corpo nas suas partes constituintes e dividimo-lo nas suas partes integrantes.

Sra. B.: Exatamente. Por conseguinte, se um corpo for constituído por uma só substância, embora possa ser divido nas suas partes integrantes, não é possível decompô-lo. Tais corpos são então chamados de simples ou elementares, uma vez que são os elementos de que são compostos todos os outros corpos. Os corpos compostos são os que consistem em mais de um desses princípios elementares.

Em Conversations, as experiências são descritas com tal realismo que o leitor as consegue "viver"; algumas vêm acompanhadas dos respetivos esquemas de montagem, desenhados pela própria autora (Figura 5). $\mathrm{O}$ diálogo seguinte, a propósito de uma experiência destinada a ilustrar o conceito de "atração" entre compostos, é bem revelador da clareza, detalhe e vivacidade das descrições (páginas 17 a 19 de [16]):

Sra. B.: [...] se eu verter algum deste líquido (chamado ácido nítrico) sobre o pedaço de cobre contido no copo, a sua forte atração faz com que cada uma das partículas do cobre se combine com uma partícula de ácido; formando juntas um novo corpo, totalmente diferente tanto do cobre como do ácido. Notas a comoção interna que já começa a ocorrer?

Emily: O ácido ... parece dissolver muito rapidamente o cobre!

Sra. B.: Dessa forma ele vai reduzir o cobre a partes mais minúsculas do que aquelas que possivelmente se poderiam obter por uma ação mecânica. Mas, como o ácido só consegue atuar na superfície do metal, vai demorar algum tempo até que a união destes dois corpos se complete.

Podes, no entanto, ver já como este composto é totalmente diferente dos seus ingredientes: não é incolor como o ácido, nem duro, pesado e amarelo como o cobre. Se o provasses, já não irias notar a acidez do ácido. De momento apresenta-se como um líquido azul mas quando a união ficar completa e a água - na qual o ácido estava diluído - for evaporada, assumirá a forma de cristais regulares de uma bela cor azul perfeitamente transparente. Posso mostrar-te um exemplar desses, porque para o efeito já preparei alguns. 
Caroline: Que bonitos que são na cor, na forma e na transparência!

Emily: Não deverá existir melhor exemplo da atração química!

\section{O APRENDIZ DE ENCADERNADOR E DE QuímICA}

As sucessivas edições de Conversations on Chemistry foram sendo atualizadas por Jane Marcet ao sabor dos desenvolvimentos da Química, para os quais estava sempre alerta. A esse respeito é interessante reparar na nota inicial que incluiu na quinta edição inglesa [16]:

"A autora, nesta quinta edição, esforçou-se por incluir as principais descobertas levadas a cabo nos últimos quatro anos na Ciência Química bem como as várias importantes aplicações que originaram, como é o caso da luz de gás e da lanterna de segurança dos mineiros."

Na oitava edição, Jane introduziu as "últimas descobertas do eletromagnetismo e a doutrina das proporções definidas" [2].

A sua permanente preocupação em atualizar Conversations está bem patente na carta que, aos 71 anos, escreveu àquele que em jovem lhe terá encadernado o seu livro (Figura 6) [2]:

Caro Sr. Faraday, li esta manhã no Athenaeum uma notícia sobre uma descoberta por si anunciada ... respeitante à identidade dos agentes imponderáveis, calor, luz e eletricidade. Encontrando-me neste momento a corrigir o meu Conversations on Chemistry, para uma nova edição, ouso tomar a liberdade de the pedir que me informe onde poderei obter uma descrição desta descoberta. Receio que seja de uma natureza demasiado complexa para poder ser adaptada às minhas jovens alunas mas não me decidi ainda a publicar a nova edição sem a mencionar. Por conseguinte, mantenho de lado as folhas das provas de Conversations referentes à eletricidade as quais estive esta manhã a rever - até receber a sua resposta, na esperança de a conseguir incluir.

Quando Jane morreu, em 1858, Michael Faraday escreveu a seguinte carta a Auguste de la Rive, amigo da família Marcet [4]:
[...] a Sra. Marcet era uma boa amiga minha, como o deverá ter sido de todos os seres humanos. Entrei para a oficina de um livreiro e encadernador aos treze anos de idade, em 1804, e permaneci lá oito anos, encadernando livros a maior parte do tempo. Foi nesses livros, lidos após as horas de trabalho, que a minha filosofia se iniciou; havia dois que me ajudaram especialmente, a "Enciclopédia Britânica", onde obtive as minhas primeiras noções de eletricidade, e o Conversations on Chemistry da Sra. Marcet, que me forneceu os meus alicerces naquela ciência.

Não julgue que eu fosse um profundo pensador ou, mesmo, considerado como uma pessoa precoce; era antes muito vivaço e imaginativo - tanto podia acreditar nos contos das "mil e uma noites" como na "Enciclopédia". Contudo, os factos eram importantes para mim, que foi o que me salvou; eu acreditava num facto se ele se conseguisse sustentar em todos os seus detalhes. Quando consultei o livro da Sra.
Marcet, a propósito das experiências que tinha possibilidade de realizar, e verifiquei que estas concordavam com os factos, tal como eu os podia entender, senti que tinha encontrado, no conhecimento químico, uma âncora de sustentação à qual rapidamente me agarrei. Daí a minha profunda veneração pela Sra. Marcet: primeiro como uma pessoa que me deu grande prazer e satisfação pessoal e, depois, como alguém capaz de transmitir a verdade e os princípios daqueles infindáveis domínios do conhecimento das coisas naturais, a uma mente jovem, não instruída e inquisidora.

\section{As VOLTAS QUE O PARAFUSO DÁ}

Jane Marcet, detentora de um espírito averiguador e de um pensamento claro e muito lógico, a que se aliava uma enorme capacidade de comunicação, foi, na primeira metade do séc. XIX, uma notável pedagoga e divulgadora da ciência e das disciplinas saídas do lluminismo, muito

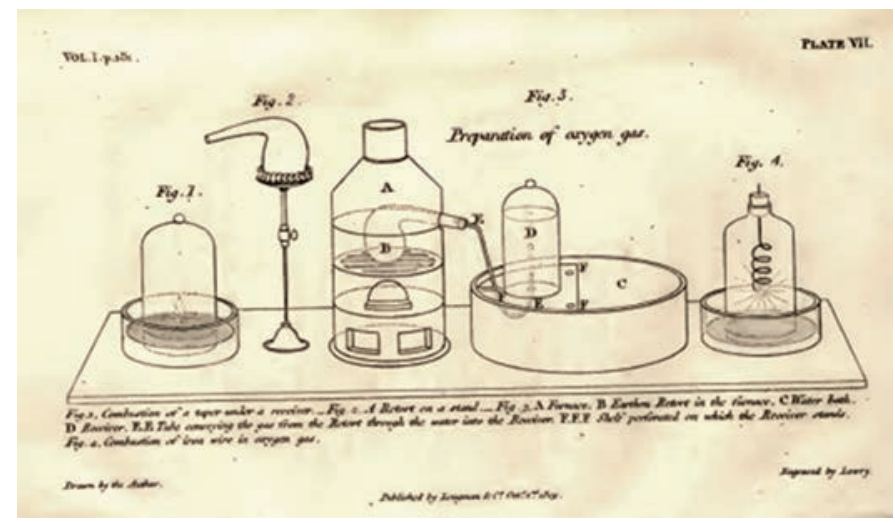

Figura 5 - Ilustração de Conversations on Chemistry relativa à preparação do oxigénio e às combustões (página 181 da quinta edição inglesa)

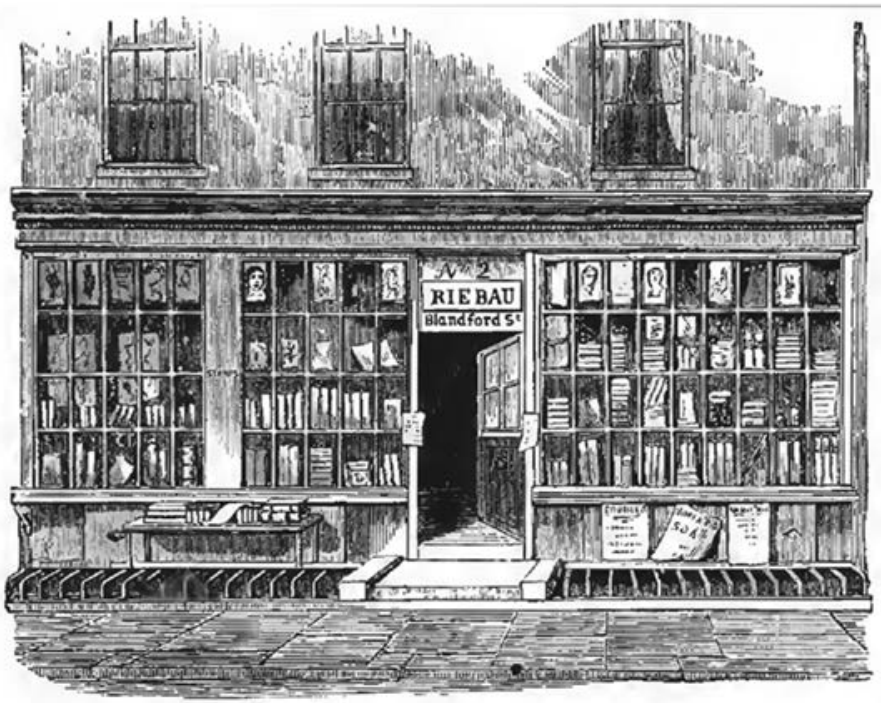

Figura 6 - Livraria e oficina de encadernação de George Riebau onde, em jovem, Michael Faraday trabalhou como encadernador 
apreciada, sobretudo, pelo sexo feminino, que não recebia educação formal em ciência. Conversations on Chemistry, a obra que a imortalizou e que inegavelmente teve o contributo do marido Alexander Marcet, químico ilustre - dominou sobremaneira a instrução elementar em Química durante várias gerações. Conversations teve dezasseis edições em Inglaterra e foi traduzido para francês e alemão. Nos Estados Unidos da América, o seu impacto foi igualmente admirável: em 1853 já tinha vendido 160000 exemplares. Thomas Jefferson (17431826), terceiro presidente do país ele próprio um apaixonado da Química - recomendava o livro da Sra. Marcet (que não faltava na sua biblioteca) aos que a desejassem aprender [19].

O facto, pouco inocente, de as três personagens do popular livro serem do sexo feminino, teve a consequência óbvia de contribuir para o estabelecimento da Química como uma ciência não destinada exclusivamente aos homens. Uma das consequências do interesse das mulheres pela Química, e do seu progressivo envolvimento nela, foi a necessidade da criação de instituições de ensino científico destinadas a raparigas.

As repercussões da obra de Jane Marcet na sociedade ficaram testemunhadas na novela do grande escritor anglo-americano Henry James (1843-1916), The Turn of the Screw, publicada noventa e dois anos depois da primeira edição de Conversations on Chemistry. Trata-se de uma obra literária de terror psicológico cuja ação, repleta de tensão e de ambiguidade, decorre numa mansão vitoriana assombrada; as figuras centrais são o rapazinho Miles, a sua irmã Flora e a ama destes. No capítulo $X$, a aterrorizada ama - que julga ter visto um fantasma - pergunta a Flora se também vira algo estranho. A pergunta, contudo, não parece impressionar a criança, que se mostra imperturbável (página 218 de [20]):

She absolutely declined to be puzzled; she turned her eyes to the flame of the candle as if the question were as irrelevant, or at any rate as impersonal, as Mrs. Marcet or nine-times-nine.
A referência a Jane Marcet destina-se a frisar que a pergunta da ama perturbou tanto Flora como a teriam perturbado as comuns perguntas sobre assuntos escolares. "Nove vezes nove" apresenta um sentido duplo: se por um lado é uma alusão à tabuada, que as crianças (então!) tinham de saber de cor; por outro, apela ao domínio do sobrenatural, nomeadamente ao momento da $3 .^{a}$ cena do $1 .^{\circ}$ ato de Macbeth de Shakespeare, em que uma das três bruxas lança um feitiço sobre um marinheiro ${ }^{1}$

A novela de Henry James tem sido objeto das mais variadas adaptações ao longo dos tempos, tanto para o palco, como para o ecrã; as mais notáveis serão a ópera homónima, de Benjamin Britten (1954), e o filme The Innocents, de Jack Clayton (1961), Figura 7.

\section{AgRAdECIMENTOS}

O autor agradece as valiosas sugestões e/ou a leitura atenta do manuscrito às seguintes pessoas: João Costa, Jorge Calado, Ana Paula Esteves e avaliador(a).

\section{NotA}

1 Weary se'n nights nine times nine Shall he dwindle, peak and pine: Though his bark cannot be lost, Yet it shall be tempest-tost. (Página 859 de [21])

\section{REFERÊNCIAS}

[1] L. Rosenfeld, Clinic. Chem., 2001, 47, 784-792.

[2] E. V. Armstrong, J. Chem. Educ., 1938, 53-57.

[3] E. C. Patterson, British Journal for the History of Science, 1969, 4, 311-339.

[4] A. de la Rive, Biliothèque Universelle - Revue Suisse et Étrangère, 1859, 64(4), 445-468.
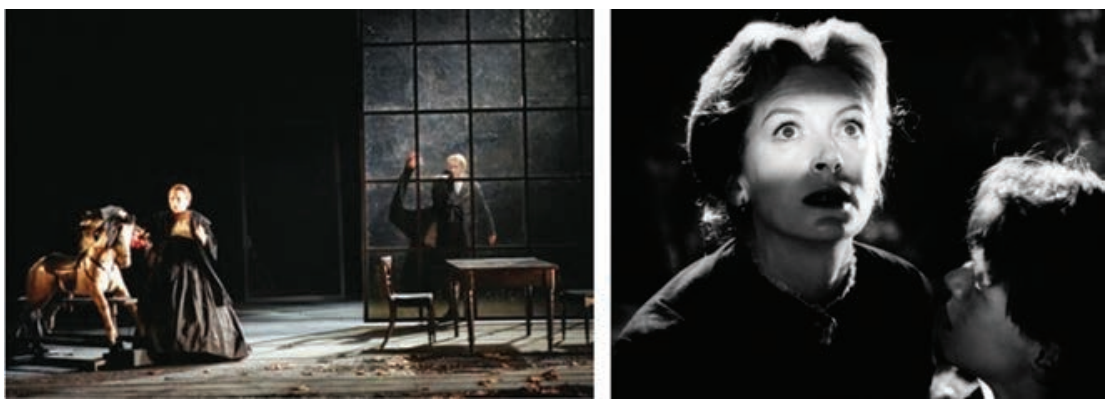

Figura 7 - Cena da ópera The Turn of the Screw de Benjamin Britten, numa produção de 2007 da English National Opera (esquerda); Deborah Kerr no papel da ama no filme de 1961 de Jack Clayton The Innocents (direita) 